\title{
Prevalence and Complications of Postoperative Transfusion for Cervical Fusion Procedures in Spine Surgery: An Analysis of 11,588 Patients from the American College of Surgeons National Surgical Quality Improvement Program Database
}

\author{
Ahmed Aoude ${ }^{1 *}$, Sultan Aldebeyan ${ }^{1,2 *}$, Maryse Fortin ${ }^{1}$, Anas Nooh ${ }^{1,3}$, \\ Peter Jarzem ${ }^{1}$, Jean A. Ouellet ${ }^{1}$, Michael H. Weber ${ }^{1}$ \\ ${ }^{1}$ McGill Scoliosis \& Spine Centre, McGill University Health Centre, Montreal, Canada \\ ${ }^{2}$ Department of Orthopedic Surgery, King Fahad Medical City, Riyadh, Saudi Arabia \\ ${ }^{3}$ Department of Orthopedic Surgery, King Abdulaziz University, Jeddah, Saudi Arabia
}

\section{Study Design: Retrospective cohort study.}

Purpose: The purpose of this study was to assess the rate of blood transfusion after cervical fusion surgery, and its effect on complication rates.

Overview of Literature: Cervical spine fusions have gained interest in the literature since these procedures are now ever more frequently being performed in an outpatient setting with few complications.

Methods: The American College of Surgeons National Surgical Quality Improvement Program (ACS-NSQIP) database was used to identify patients that underwent cervical fusion from 2010 to 2013. Multivariate regression analysis was used to determine postoperative complications associated with transfusion and cervical fusion.

Results: We identified 11,588 patients who had cervical fusion between 2010 and 2013. The rate of blood transfusion following cervical fusion found to be $1.47 \%$. All transfused patients were found to have increased risk of venous thromboembolism (TBE) (odds ratio [OR], 3.19; 95\% confidence interval [95\% Cl], 1.16-8.77), myocardial infarction (MI) (OR, 9.12; 95\% Cl, 2.53-32.8), increased length of stay (LOS) (OR, 28.03; 95\% Cl, 14.28-55.01) and mortality (OR, 4.14; 95\% Cl, 1.44-11.93). Single level fusion had increased risk of TBE (OR, 3.37; 95\% $\mathrm{Cl}, 1.01-11.33$ ), MI (OR, 10.5; 95\% Cl, 1.88-59.89), and LOS (OR, 14.79; 95\% Cl, 8.2-26.67). Multilevel fusion had increased risk of TBE (OR, 5.64; 95\% Cl, 1.15-27.6), surgical site infection (OR, 16.29; 95\% Cl, 3.34-79.49), MI (OR, 10.84; 95\% Cl, 2.01-58.55), LOS (OR, 26.56; $95 \% \mathrm{Cl}, 11.8-59.78)$, and mortality (OR, 10.24; 95\% $\mathrm{Cl}, 2.45-42.71)$. Patients who had anterior cervical discectomy and fusion surgery and received a transfusion had an increased risk of TBE (OR, 4.87; 95\% Cl, 1.04-22.82), surgical site infection (OR, 9.73; 95\% Cl, 2.14-44.1), $\mathrm{MI}(\mathrm{OR}, 9.88 ; 95 \% \mathrm{Cl}, 1.87-52.2)$, increased LOS of more than 2 days (OR, 28.34; 95\% Cl, 13.79-58.21) and increase in mortality (OR, 6.3; $95 \% \mathrm{Cl}, 1.76-22.48)$. While, transfused patients who had posterior fusion surgery had increased risk of $\mathrm{MI}(\mathrm{OR}, 10.45 ; 95 \% \mathrm{Cl}, 1.42-77.12)$ and increased LOS of more than 6 days (OR, 4.42; 95\% Cl, 2.68-7.29).

Conclusions: Our results demonstrate that although cervical fusions can be done as outpatient procedures special precautions and investigations should be done for patients who receive transfusion after cervical fusion. These patients are demonstrated to have higher rate of $\mathrm{MI}, \mathrm{TBE}$, wound infection and mortality when compared to those who do not receive transfusion.

Keywords: Cervical spine; Fusion; Blood transfusion; National Surgical Quality Improvement Program; Complications

Received Dec 14, 2016; Revised Mar, 22, 2017; Accepted Apr 20, 2017

Corresponding author: Michael H. Weber

McGill University Health Centre, Montreal General Hospital Site A5-169, 1650 Cedar Ave, Montreal, Quebec H3G 1A4, Canada

Tel: +1-514-934-1934, Fax: +1-514-934-8320, E-mail: Michael.Weber@mcgill.ca

*These authors contributed equally to this work. 


\section{Introduction}

Cervical spine fusion has gained interest in the literature since these procedures are now ever more frequently being performed in an outpatient setting with few complications and acceptable results [1-3]. These studies demonstrate that the rate of complications associated with anterior cervical discectomy and fusion (ACDF) as well as simple posterior cervical fusion (PCF) are low. Sheperd and Young [2] showed that the complication rate in outpatient ACDF was as low as $3.9 \%$ with $100 \%$ patient satisfaction. McGirt et al. [1] reported a low readmission rate (2.2\%) for patients in ACDF outpatient procedures. Cerebrospinal fluid leak, myocardial infarction, neurological deficit and need for postoperative transfusion were among the rare complications reported.

Spine surgeries with fusion have been shown to have high complications rates. Bohl et al. [4] looked at the timing of these complications in a large cohort of patients undergoing all types of spine fusion surgeries. The timing of postoperative transfusion was shown to occur immediately after surgery. Although, the rate of postoperative transfusion in patients in cervical fusion patients is thought to be low, little studies have focused on the effects of transfusion in cervical spine fusion patients. However, multiple studies have shown that higher rates of surgical site infections were associated with receiving blood transfusion [5-7]. In a recent study, the effect of transfusion on primary posterior lumbar surgery was shown to be associated with increased complications [8]. To our knowledge, few studies have reported on postoperative complications in cervical spine fusion only [9-11], and most have been limited by the small sample sizes. In this study, we aim to assess the rate of blood transfusion after cervical fusion surgery, and its effect, if any on complication rates from the National Surgical Quality Improvement Program (NSQIP) database that represents both academic and community centers in North America. Therefore, analyzed data in this database represents a greater population of patients undergoing cervical spine fusion.

\section{Materials and Methods}

This study received an exemption by the Institutional Review Board of the McGill University Health Center (MUHC).

\section{Database source and patient selection}

We retrospectively analyzed data for all cervical fusion surgeries captured in the American College of Surgeons National Surgical Quality Improvement Program (ACSNSQIP) database between 2010 and 2013. This database includes data from over 400 participating hospitals in the United States and Canada. Data acquisition has been validated in the literature $[12,13]$ and is collected in 8-day cycles and closely monitored weekly to ensure accuracy of data. The database captures over 130 variables for each patient. Variables collected include patient demographics, preoperative lab results, comorbidities, procedure type, intraoperative variables such as length of surgery, postoperative complications and rates of re-admission and reoperation for a period of 30 days.

We identified all patients who had cervical spine fusion between 2010 and 2013 (anterior and posterior fusions where included). We identified patients who underwent ACDF and posterior fusion with the following Current Procedural Terminology codes: 22551, 22554 and 22600. To identify patients who underwent multi-level surgery we used the following codes: 22552, 63076, S2361, 22845, 22846 , and 22847. Only patients 18 years and older with complete documented variables were included in the study.

\section{Outcomes and explanatory variables}

The main outcome of this study was the incidence and effect of intraoperative or postoperative transfusion on complications. Transfusion was defined as any patient requiring at least one unit of packaged red blood cells in the operative period. This period was defined by NSQIP as any transfusion received from the surgical time up to 72 hours postoperatively.

Demographics characteristics included sex, age, and race. Comorbidities recorded in ACS-NSQIP included body mass index (BMI) (calculated from each patient's height and weight $\left[\mathrm{kg} / \mathrm{m}^{2}\right]$ ), history of diabetes (recorded as history of type 1 or type 2 diabetes), smoking, dyspnea (classified as dyspnea at rest or at moderate excretion), chronic obstructive pulmonary disease (COPD), congestive heart failure (CHF), dialysis, hypertension, bleeding disorder, steroids intake for chronic diseases, functional health status prior to surgery and American Society of Anaesthesiologist (ASA) class. 
Table 1. All cervical fusion patients

\begin{tabular}{|c|c|c|c|}
\hline \multirow{2}{*}{ Demongraphic characteristics } & \multicolumn{2}{|c|}{ Cervical fusion } & \multirow{2}{*}{$p$-value } \\
\hline & Not transfused $(n=11,417)$ & Transfused $(n=171)$ & \\
\hline Age (yr) & $36.4 \pm 11.6$ & $45.5 \pm 13.2$ & $<0.001$ \\
\hline Sex & & & 0.965 \\
\hline Woman & 51.1 & 50.9 & \\
\hline Men & 48.9 & 49.1 & \\
\hline Race & & & 0.197 \\
\hline White & 82.0 & 76.6 & \\
\hline Black or African American & 9.5 & 13.5 & \\
\hline American Indian or Native & 0.5 & 0 & \\
\hline Native Hawaiian or Pacific Islander & 0.3 & 0.6 & \\
\hline Asian & 1.8 & 3.5 & \\
\hline Unknown & 5.9 & 5.9 & \\
\hline \multicolumn{4}{|l|}{ Comorbidity } \\
\hline $\mathrm{BMI}\left(\mathrm{kg} / \mathrm{m}^{2}\right)$ & $30.0 \pm 6.6$ & $28.5 \pm 7.1$ & 0.002 \\
\hline Diabetes & & & $<0.001$ \\
\hline Type I & 5.0 & 8.7 & \\
\hline Type II & 10.5 & 18.7 & \\
\hline Smoking & 30.6 & 23.4 & 0.04 \\
\hline Dyspnea & & & $<0.001$ \\
\hline At rest & 0.4 & 2.9 & \\
\hline Moderate exertion & 6.0 & 6.4 & \\
\hline COPD & 4.5 & 11.7 & $<0.001$ \\
\hline CHF & 0.2 & 1.2 & 0.005 \\
\hline Dialysis & 0.4 & 5.9 & $<0.001$ \\
\hline Hypertension & 45.7 & 72.5 & $<0.001$ \\
\hline Bleeding disease & 1.3 & 8.2 & $<0.001$ \\
\hline Steroids & 3.6 & 8.2 & 0.002 \\
\hline \multicolumn{4}{|l|}{ ASA class } \\
\hline 1 (No disturbance) & 3.8 & 0 & $<0.001$ \\
\hline 2 (Mild disturbance) & 54.3 & 19.9 & \\
\hline 3 (Severe disturbance) & 39.7 & 57.9 & \\
\hline 4 (Life-threatening disturbance) & 2.2 & 22.2 & \\
\hline 5 (Moribund) & 0.01 & 0 & $<0.001$ \\
\hline \multicolumn{4}{|l|}{ Functional health status prior surgery } \\
\hline Independent & 97.8 & 89.5 & \\
\hline Partially dependent & 2.0 & 8.2 & \\
\hline Totally dependent & 0.2 & 2.3 & \\
\hline \multicolumn{4}{|l|}{ Clinical characteristic } \\
\hline Blood transfusion within $48 \mathrm{hr}$ preoperatively (\%) & 0.2 & 5.3 & $<0.001$ \\
\hline Operation time & $130.4 \pm 73.1$ & $273.1 \pm 139.0$ & $<0.001$ \\
\hline Elective surgery & 92.4 & 66.1 & $<0.001$ \\
\hline
\end{tabular}


Table 1. Continued

\begin{tabular}{|c|c|c|c|}
\hline \multirow{2}{*}{ Demongraphic characteristics } & \multicolumn{2}{|c|}{ Cervical fusion } & \multirow{2}{*}{$p$-value } \\
\hline & Not transfused $(\mathrm{n}=11,417)$ & Transfused $(\mathrm{n}=171)$ & \\
\hline Outpatient & & & $<0.001$ \\
\hline Inpatient & 19.6 & 0.6 & \\
\hline Outpatient & 80.4 & 99.4 & \\
\hline Return to operation room & 1.6 & 10.5 & $<0.001$ \\
\hline Multilevel surgery & 72.0 & 36.8 & $<0.001$ \\
\hline ACDF & 92.2 & 48.0 & $<0.001$ \\
\hline Preoperative hematocrit & $41.2 \pm 4.2$ & $35.5 \pm 5.9$ & $<0.001$ \\
\hline Preoperative platelet count & $245 \pm 67.1$ & $243.1 \pm 90.4$ & 0.586 \\
\hline Preoperative WBC & $7.6 \pm 2.5$ & $7.6 \pm 2.8$ & 0.878 \\
\hline Preoperative serum creatinine & $0.9 \pm 0.5$ & $1.2 \pm 1.5$ & $<0.001$ \\
\hline Preoperative BUN & $15.2 \pm 6.8$ & $19.2 \pm 13.4$ & $<0.001$ \\
\hline Preoperative serum sodium & $139.1 \pm 2.7$ & $138.7 \pm 3.2$ & 0.02 \\
\hline
\end{tabular}

Values are presented as mean+standard deviation or percentage.

$\mathrm{BMI}$, body mass index; COPD, chronic obstructive pulmonary disease; CHF, congestive heart failure; ASA, American Society of Anaesthesiologist; ACDF, anterior cervical discectomy and fusion; WBC, white blood cell; BUN, blood urea nitrogen.

Clinical characteristics variables included blood transfusion within 48 hours preoperatively, operative time elective surgery, inpatient, return to the operation room and preoperative laboratory values (e.g., hematocrit, platelet count, white blood count, serum creatinine, blood urea nitrogen $[\mathrm{BUN}]$ and serum sodium). Postoperative complications included deep surgical site infection, venous thromboembolism, superficial surgical site infection, myocardial infarction (MI), length of hospital stay and death.

\section{Statistical analysis}

All statistical analyses were conducted using Stata ver. 12.0 (StataCorp, LP, College Station, TX, USA). Person chi-squared for categorical variables and student $t$ tests for continuous variable were used to compare patient demographic and preoperative clinical characteristics between patients who received blood transfusion intraoperatively and those who did not. Multivariate logistic regression was conducted to determine independent risk factors for blood transfusion; only preoperative predictor variables with a $p<0.2$ in univariate analysis were included in the regression model. Multivariate logistic regression was also used to compare the occurrence of complications between patient who received a blood transfusion and those who did not. Multivariate analysis controlled for demographic and comorbidity variables. A separate multivariable analysis was performed to examined postoperative complications according to the surgical procedure performed (e.g., single level, multiple level, anterior fusion and posterior fusion).

\section{Results}

We identified 11,588 patients who had cervical spine fusion between 2010 and 2013. The overall prevalence of transfusion was $1.47 \%$. A total of 10,613 patients had ACDF (prevalence of transfusion of $0.77 \%$ ) while only 975 patients had PCF (prevalence of transfusion of 9.13\%).

For all 11,588 patients who underwent cervical spine fusion, patients who received postoperative transfusion were found to have multiple statistically significant different characteristics to those who did not require transfusion. These characteristics included: older age, lower BMI, less likely to be diabetics, more likely to have dyspnea, less likely to be smokers, higher incidence of COPD, higher likelihood of having CHF, higher incidence of dialysis, have more hypertension, higher bleeding disorders, higher ASA classification and lower functional status as illustrated in Table 1.

Preoperative characteristics that were associated with 
Table 2. Association of blood transfusion with adverse outcomes for all cervical fusion patients

\begin{tabular}{|c|c|c|c|c|c|}
\hline \multirow{2}{*}{ Outcome } & \multirow{2}{*}{$\begin{array}{l}\text { Not transfused }(\%) \\
\qquad(\mathrm{n}=11,417)\end{array}$} & \multirow{2}{*}{$\begin{array}{l}\text { Transfused }(\%) \\
(n=171)\end{array}$} & \multicolumn{3}{|c|}{ Multivariate logistic regression ${ }^{\mathrm{a})}$} \\
\hline & & & Odds ratio & 95\% Confidence interval & $p$-value \\
\hline Deep surgical site infection & 0.2 & 0.6 & 0.93 & $0.11-7.75$ & 0.952 \\
\hline Venous thromboembolism & 0.4 & 3.5 & $3.19^{b)}$ & $1.16-8.77^{b)}$ & $0.024^{b)}$ \\
\hline Superficial surgical site Infection & 0.4 & 1.2 & 1.71 & $0.37-7.88$ & 0.487 \\
\hline Myocardial infarction & 0.2 & 2.9 & $9.12^{b)}$ & $2.53-32.80^{b)}$ & $0.001^{b)}$ \\
\hline Extended length of stay (>2 day) & 20.0 & 94.2 & $28.03^{b)}$ & $14.28-55.01^{b)}$ & $<0.001^{\text {bl }}$ \\
\hline Death & 0.3 & 4.1 & $4.14^{\mathrm{bl}}$ & $1.44-11.93^{b)}$ & $0.008^{b)}$ \\
\hline
\end{tabular}

a) Each line represent a separate multivariate logistic regression analysis for each variable and adjusted odds ratio and $p$-value by controlling for multilevel surgery and surgical approach, as well as all demographics and comorbidities found in Table 1 ; b) Statistical significance ( $p<0.05)$.

Table 3. Association of blood transfusion with adverse outcomes for all single level cervical fusion patients

\begin{tabular}{|c|c|c|c|c|c|}
\hline \multirow{2}{*}{ Outcome } & \multirow{2}{*}{$\begin{array}{l}\text { Not transfused }(\%) \\
\qquad(n=3,193)\end{array}$} & \multirow{2}{*}{$\begin{array}{l}\text { Transfused }(\%) \\
\qquad(\mathrm{n}=108)\end{array}$} & \multicolumn{3}{|c|}{ Multivariate logistic regression ${ }^{\text {a) }}$} \\
\hline & & & Odds ratio & 95\% Confidence interval & $p$-value \\
\hline Deep surgical site infection & 0.5 & 0.9 & 1.41 & $0.16-12.17$ & 0.750 \\
\hline Venous thromboembolism & 0.6 & 3.7 & $3.37^{b)}$ & $1.01-11.33^{b)}$ & $0.048^{b /}$ \\
\hline Superficial surgical site infection & 0.5 & 0 & - & - & - \\
\hline Myocardial infarction & 0.1 & 2.8 & $10.5^{b)}$ & $1.88-59.89^{b l}$ & $0.007^{b)}$ \\
\hline Extended length of stay ( $>3$ days) & 21.3 & 86.1 & $14.79^{b l}$ & $8.20-26.67^{b)}$ & $<0.001^{b)}$ \\
\hline Death & 0.3 & 2.8 & 2.39 & $0.50-11.29$ & 0.272 \\
\hline
\end{tabular}

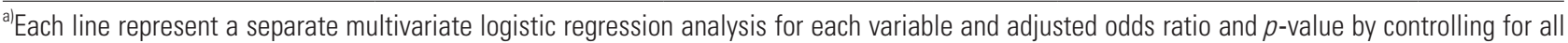
demographics and comorbidities found in Table 1; ${ }^{b}$ Statistical significance $(p<0.05)$.

receiving a blood transfusion after cervical fusion were: increased requirements of preoperative transfusion, higher BUN, higher creatinine levels, lower hematocrit, lower sodium levels, non-elective surgeries (including emergency surgery) and longer operative times.

Multivariate analysis was performed to control for all patients' characteristics to predict risk of complication in patients that have received blood transfusion. When all 11,588 patients were included in the analysis, patients who received transfusion were found to have increased risk of venous thromboembolism (odds ratio [OR], 3.19; 95\% confidence interval [95\% CI] 1.16-8.77), increased MI (OR, 9.12; CI, 2.53-32.8), increased length of stay of more than 2 days (OR, 28.03; CI, 14.28-55.01) and increased mortality (OR, 4.14; 95\% CI, 1.44-11.93) (Table 2).

\section{Procedural specifics}

Transfused patients treated with single level fusion had increased risk of developing venous thromboembolism (OR, 3.37; 95\% CI, 1.01-11.33), increased MI (OR, 10.5; 95\% CI, 1.88-59.89), and increased length of stay of more than 3 days (OR, 14.79; 95\% CI, 8.2-26.67) (Table 3).

While transfused patients treated with multilevel fusion had increased risk of developing venous thromboembolism (OR, 5.64; 95\% CI, 1.15-27.6), increased surgical site infection (OR, 16.29; 95\% CI, 3.34-79.49), increased MI (OR, 10.84; CI, 2.01-58.55), increased length of stay of more than 2 days (OR, 26.56; 95\% CI, 11.8-59.78) and increase in mortality (OR, 10.24; 95\% CI, 2.45-42.71) (Table 4). 
Table 4. Association of blood transfusion with adverse outcomes for all multi-level cervical fusion patients

\begin{tabular}{|c|c|c|c|c|c|}
\hline \multirow{2}{*}{ Outcome } & \multirow{2}{*}{$\begin{array}{l}\text { Not transfused }(\%) \\
\qquad(n=8,224)\end{array}$} & \multirow{2}{*}{$\begin{array}{l}\text { Transfused }(\%) \\
\qquad(\mathrm{n}=63)\end{array}$} & \multicolumn{3}{|c|}{ Multivariate logistic regression ${ }^{\mathrm{a})}$} \\
\hline & & & Odds ratio & 95\% Confidence interval & $p$-value \\
\hline Deep surgical site infection & 0.1 & 0 & - & - & - \\
\hline Venous thromboembolism & 0.3 & 3.2 & $5.64^{b)}$ & $1.15-27.6^{b)}$ & $0.032^{b)}$ \\
\hline Superficial surgical site infection & 0.3 & 3.2 & $16.29^{b)}$ & $3.34-79.49^{b)}$ & $0.001^{b)}$ \\
\hline Myocardial infarction & 0.2 & 3.2 & $10.84^{b)}$ & $2.01-58.55^{b l}$ & $0.006^{b l}$ \\
\hline Extended length of stay (>2 day) & 15.5 & 88.9 & $26.56^{b)}$ & $11.80-59.78^{b)}$ & $<0.001^{\text {b) }}$ \\
\hline Death & 0.2 & 6.35 & $10.24^{b)}$ & $2.45-42.71^{\mathrm{bl}}$ & $<0.001^{\mathrm{bl}}$ \\
\hline
\end{tabular}

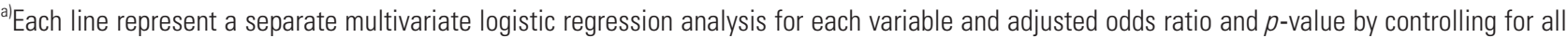
demographics and comorbidities found in Table 1; ${ }^{b}$ Statistical significance $(p<0.05)$.

Patients who had ACDF surgery and received a transfusion were found to have multiple significant differences in demographics and clinical characteristics compared to those who did not require transfusion. These patients were older, had lower BMI, more likely to be diabetics, dyspneic, had higher incidence of COPD, CHF, dialysis, have more hypertension, higher bleeding disorders, higher ASA classification and lower functional status. Additionally, they were more likely to be done in an inpatient settings and less likely in an elective settings (Table 4). On the other hand, Patients who had posterior fusion surgery and received a transfusion were found to be older, had higher incidence of CHF, dialysis, hypertension, bleeding disorders and higher ASA classification (Table 5).

Patients who had ACDF surgery and received a transfusion were found to have multiple significant differences in demographics and clinical characteristics compared to those who did not require transfusion. These patients were older, had lower BMI, more likely to be diabetics, dyspneic, had higher incidence of COPD, CHF, dialysis, have more hypertension, higher bleeding disorders, higher ASA classification and lower functional status. Additionally, they were more likely to be done in an inpatient setting and less likely in an elective setting (Table 5). After controlling all confounders, they had an increased risk of venous thromboembolism (OR, 4.87; 95\% CI, 1.04-22.82), increased surgical site infection (OR, 9.73; CI, 2.14-44.1), increased MI (OR, 9.88; 95\% CI, 1.87-52.2), increased length of stay of more than 2 days (OR, 28.34; 95\% CI, 13.79-58.21) and increase in mortality (OR, 6.3; 95\% CI, 1.76-22.48) (Table 6). On the other hand, transfused patients who had posterior fusion surgery were found to be older, had higher incidence of CHF, dialysis, hypertension, bleeding disorders and higher ASA classification (Table 7). After controlling for all confounders, they had increased risk of MI (OR, 10.45; 95\% CI, 1.42-77.12) and increased length of stay of more than 6 days (OR, 4.42; 95\% CI, 2.68-7.29) (Table 8).

\section{Discussion}

This study retrospectively analyzed a large database to determine predictive factors and complications rates associated with giving postoperative blood transfusion in cervical fusion surgery. This is the first research specifically looking at a large cohort of cervical fusion patients and identifying risk factors associated with postoperative complications. Patients with both anterior and posterior fusion where analysed as well as patients with single level or multilevel surgeries.

Only gender and age did not show significant difference between patients who were transfused and those who were not. However, other patient characteristics were associated with the need for a transfusion after undergoing cervical fusion surgery; these were found to be: older age, dyspnea, COPD, CHF, dialysis, hypertension, bleeding disorders, high ASA classification and poor functional status. Preoperative blood test results which were associated with an increased risk of requiring postoperative transfusion included lower hematocrit, higher BUN, lower sodium levels, higher creatinine levels. These results are consistent with factors identified to be associated with transfusion for other surgical procedures in the literature [8,14-16]. Therefore, we suggest that these factors can be 
Table 5. Demographics and clinical characteristics of patients who underwent ACDF

\begin{tabular}{|c|c|c|c|}
\hline \multirow{2}{*}{ Demographic characteristics } & \multicolumn{2}{|c|}{ ACDF } & \multirow{2}{*}{$p$-value } \\
\hline & Not transfused $(n=10,531)$ & Transfused $(\mathrm{n}=82)$ & \\
\hline Age (yr) & $53.9 \pm 11.5$ & $61.1 \pm 14.8$ & $<0.001$ \\
\hline Sex & & & 0.06 \\
\hline Woman & 51.7 & 62.2 & \\
\hline Men & 48.3 & 37.8 & \\
\hline Race (\%) & & & 0.001 \\
\hline White & 82.3 & 74.4 & \\
\hline Black or African American & 9.3 & 17.1 & \\
\hline American Indian or Native & 0.5 & 0 & \\
\hline Native Hawaiian or Pacific Islander & 0.3 & 1.2 & \\
\hline Asian & 1.7 & 6.1 & \\
\hline Unknown & 5.9 & 1.2 & \\
\hline \multicolumn{4}{|l|}{ Comorbidities } \\
\hline $\mathrm{BMI}\left(\mathrm{kg} / \mathrm{m}^{2}\right)$ & $30.1 \pm 6.6$ & $28.0 \pm 7.7$ & 0.005 \\
\hline Diabetes & & & 0.004 \\
\hline Type I & 5.0 & 12.2 & \\
\hline Type II & 10.3 & 14.6 & \\
\hline Smoking & 30.5 & 29.3 & 0.81 \\
\hline Dyspnea & & & $<0.001$ \\
\hline At rest & 0.4 & 3.7 & \\
\hline Moderate exertion & 5.8 & 4.9 & \\
\hline COPD & 4.3 & 11.0 & 0.003 \\
\hline CHF & 0.2 & 0.0 & 0.71 \\
\hline Dialysis & 0.3 & 8.5 & $<0.001$ \\
\hline Hypertension & 44.8 & 64.6 & $<0.001$ \\
\hline Bleeding disease & 1.2 & 8.5 & $<0.001$ \\
\hline Steroids & 0.5 & 2.4 & 0.02 \\
\hline ASA class & & & $<0.001$ \\
\hline 1 (No disturbance) & 3.9 & 0 & \\
\hline 2 (Mild disturbance) & 55.8 & 20.7 & \\
\hline 3 (Severe disturbance) & 38.5 & 63.4 & \\
\hline 4 (Life-threatening disturbance) & 1.8 & 15.9 & \\
\hline Functional health status prior surgery & & & $<0.001$ \\
\hline Independent & 98.1 & 91.5 & \\
\hline Partially dependent & 1.7 & 6.1 & \\
\hline Totally dependent & 0.2 & 2.4 & \\
\hline \multicolumn{4}{|l|}{ Clinical characteristic } \\
\hline Blood transfusion within $48 \mathrm{hr}$ preoperatively & 0.1 & 4.9 & $<0.001$ \\
\hline Operation time & $127.2 \pm 70.4$ & $267.8 \pm 156.1$ & $<0.001$ \\
\hline Elective surgery & 93.0 & 72.0 & $<0.001$ \\
\hline
\end{tabular}


Table 5. Continued

\begin{tabular}{lccc} 
& \multicolumn{3}{c}{ ACDF } \\
Demographic characteristics & \multicolumn{3}{c}{$p$-value } \\
\cline { 2 - 3 } Outpatient & Not transfused $(n=10,531)$ & Transfused $(n=82)$ & $<0.001$ \\
\hline Inpatient & 79.2 & 98.8 & 1.2 \\
\hline Outpatient & 20.8 & 11.0 & $<0.001$ \\
\hline Return to operation room & 1.3 & 70.7 & 0.14 \\
\hline Multilevel surgery & 77.6 & $35.7 \pm 5.6$ & $<0.001$ \\
\hline Preoperative hematocrit & $41.3 \pm 4.1$ & $246.1 .1 \pm 89.9$ & 1.01 \\
\hline Preoperative platelet count & $246.1 \pm 66.7$ & $7.8 \pm 2.9$ & 0.42 \\
\hline Preoperative WBC & $7.5 \pm 2.5$ & $1.5 \pm 2.0$ & $<0.001$ \\
\hline Preoperative serum creatinine & $0.9 \pm 0.4$ & $21.3 \pm 16.8$ & $<0.001$ \\
\hline Preoperative BUN & $15.2 \pm 6.7$ & $138.5 \pm 3.2$ & 0.01 \\
\hline Preoperative serum sodium & $139.2 \pm 2.7$ & & \\
\hline
\end{tabular}

Values are presented as mean \pm standard deviation or percentage.

$\mathrm{BMI}$, body mass index; COPD, chronic obstructive pulmonary disease; CHF, congestive heart failure; ASA, American Society of Anaesthesiologist; WBC, white blood cell; BUN, blood urea nitrogen.

Table 6. Association of blood transfusion with adverse outcomes for all ACDF patients

\begin{tabular}{|c|c|c|c|c|c|}
\hline \multirow{2}{*}{ Outcome } & \multirow{2}{*}{$\begin{array}{l}\text { Not transfused }(\%) \\
\qquad(\mathrm{n}=10,531)\end{array}$} & \multirow{2}{*}{$\begin{array}{l}\text { Transfused }(\%) \\
(\mathrm{n}=82)\end{array}$} & \multicolumn{3}{|c|}{ Multivariate logistic regression ${ }^{\text {a) }}$} \\
\hline & & & Odds ratio & $95 \% \mathrm{Cl}$ & $p$-value \\
\hline Deep surgical site infection & 0.1 & 0 & - & - & - \\
\hline Venous thromboembolism & 0.3 & 2.4 & $4.87^{b)}$ & $1.04-22.82^{b)}$ & $0.044^{\text {b) }}$ \\
\hline Superficial surgical site infection & 0.3 & 2.4 & $9.73^{\mathrm{bl}}$ & $2.14-44.1^{b)}$ & $0.003^{b)}$ \\
\hline Myocardial infarction & 0.1 & 2.4 & $9.88^{b)}$ & $1.87-52.2^{b)}$ & $0.007^{b)}$ \\
\hline Extended length of stay (>2 day) & 16.0 & 89.0 & $28.34^{\text {bl }}$ & $13.79-58.21^{b)}$ & $<0.001^{\text {b) }}$ \\
\hline Death & 0.2 & 4.9 & $6.30^{\mathrm{bl}}$ & $1.76-22.48^{\mathrm{bl}}$ & $0.005^{b)}$ \\
\hline
\end{tabular}

ACDF, anterior cervical discectomy and fusion; $\mathrm{Cl}$, confidence interval.

alEach line represent a separate multivariate logistic regression analysis for each variable and adjusted odds ratio and $p$-value by controlling for all demographics and comorbidities found in Table 1; ${ }^{\text {b) }}$ Statistical significance $(p<0.05)$.

used by surgeons informing their patients as to who will require a postoperative transfusion and thus placing them at higher risk as our result have shown.

The overall incidence of transfusion in all cervical spine fusion patients was $1.47 \%$, in contrast Basques et al. [8] showed that transfusion in primary lumbar spine fusion was as high as $16.8 \%$. Although lower than transfusion need in lumbar fusion, our results showed that the rate of transfusion was highest $(9.3 \%)$ in the posterior cervical spine fusion patients in comparison to a much lower rate in patient undergoing ACDF (0.77\%). The low transfusion rate in ACDF has been reported in the literature $[17,18]$. Alam et al. [18] demonstrated that posterior fusion was at increased risk of requiring transfusion in comparison to anterior procedure in the cervical spine which is consistent with the results presented in this paper. Interestingly, that study also demonstrated higher risk of transfusion for surgeries with lower levels of arthrodesis. Although that study had a much smaller sample size they also included all levels of the spine. Our analysis showed similar results to those presented by Alam et al. [18].

The rate of complications due to transfusion should be considered. The results of this study show that an increase rate of complications can be associated to transfusion itself when controlling for factors such age, ASA, and comorbidities which have been associated with transfusion 
Table 7. Demographics and clinical characteristics of patients who underwent posterior fusion

\begin{tabular}{|c|c|c|c|}
\hline \multirow{2}{*}{ Demographic characteristics } & \multicolumn{2}{|c|}{ Posterior fusion } & \multirow{2}{*}{$p$-value } \\
\hline & Not transfused (n=886) & Transfused $(n=89)$ & \\
\hline Age (yr) & $59.6 \pm 13.1$ & $65.7 \pm 11.2$ & $<0.001$ \\
\hline $\operatorname{Sex}(\%)$ & & & 0.60 \\
\hline Woman & 43.6 & 40.4 & \\
\hline Men & 56.4 & 59.6 & \\
\hline Race & & & 0.50 \\
\hline White & 78.1 & 78.7 & \\
\hline Black or African American & 12.2 & 10.1 & \\
\hline American Indian or Native & 0.7 & 0 & \\
\hline Native Hawaiian or Pacific Islander & 0.7 & 1.2 & \\
\hline Asian & 2.6 & 1.1 & \\
\hline Unknown & 5.8 & 10.1 & \\
\hline \multicolumn{4}{|l|}{ Comorbidities } \\
\hline $\mathrm{BMI}\left(\mathrm{kg} / \mathrm{m}^{2}\right)$ & $29.2 \pm 6.7$ & $28.9 \pm 6.5$ & 0.70 \\
\hline Diabetes & & & 0.08 \\
\hline Type I & 5.6 & 5.6 & \\
\hline Type ॥ & 13.5 & 22.5 & \\
\hline Smoking & 31.3 & 18.0 & 0.009 \\
\hline Dyspnea & & & $<0.001$ \\
\hline At rest & 1.0 & 2.2 & \\
\hline Moderate exertion & 8.5 & 7.9 & \\
\hline COPD & 7.7 & 12.4 & 0.12 \\
\hline CHF & 0.5 & 2 & 0.04 \\
\hline Dialysis & 0.9 & 3.4 & 0.04 \\
\hline Hypertension & 56.8 & 79.8 & $<0.001$ \\
\hline Bleeding disease & 2.5 & 7.9 & 0.004 \\
\hline Steroids & 2.4 & 1.1 & 0.50 \\
\hline ASA class & & & $<0.001$ \\
\hline 1 (No disturbance) & 2.0 & 0 & \\
\hline 2 (Mild disturbance) & 36.9 & 19.1 & \\
\hline 3 (Severe disturbance) & 54.0 & 52.8 & \\
\hline 4 (Life-threatening disturbance) & 7.1 & 28.1 & \\
\hline Functional health status prior surgery & & & 0.07 \\
\hline Independent & 93.6 & 87.6 & \\
\hline Partially dependent & 5.8 & 10.1 & \\
\hline Totally dependent & 0.7 & 2.2 & \\
\hline \multicolumn{4}{|l|}{ Clinical characteristic } \\
\hline Blood transfusion within $48 \mathrm{hr}$ preoperatively & 1.1 & 5.6 & 0.001 \\
\hline Operation time & $127.2 \pm 70.4$ & $267.8 \pm 156.1$ & $<0.001$ \\
\hline Elective surgery & 100 & 100 & - \\
\hline
\end{tabular}


Table 7. Continued

\begin{tabular}{|c|c|c|c|}
\hline \multirow{2}{*}{ Demographic characteristics } & \multicolumn{2}{|c|}{ Posterior fusion } & \multirow{2}{*}{$p$-value } \\
\hline & Not transfused (n=886) & Transfused $(\mathrm{n}=89)$ & \\
\hline Outpatient & & & 0.02 \\
\hline Inpatient & 94.5 & 100 & \\
\hline Outpatient & 5.5 & 0.0 & \\
\hline Return to operation room & 4.5 & 10.1 & 0.02 \\
\hline Multilevel surgery & 5.9 & 5.6 & 0.92 \\
\hline Preoperative hematocrit & $39.9 \pm 4.9$ & $35.2 \pm 6.1$ & $<0.001$ \\
\hline Preoperative platelet count & $243.2 \pm 71.3$ & $240.3 \pm 91.3$ & 0.73 \\
\hline Preoperative WBC & $7.8 \pm 2.9$ & $7.4 \pm 2.7$ & 0.30 \\
\hline Preoperative serum creatinine & $1.0 \pm 0.8$ & $1.0 \pm 0.7$ & 0.60 \\
\hline Preoperative BUN & $16.2 \pm 8.0$ & $17.3 \pm 8.8$ & 0.3 \\
\hline Preoperative serum sodium & $138.7 \pm 3.1$ & $138.9 \pm 3.2$ & 0.44 \\
\hline
\end{tabular}

Values are presented as mean \pm standard deviation or percentage.

$\mathrm{BMI}$, body mass index; COPD, chronic obstructive pulmonary disease; CHF, congestive heart failure; ASA, American Society of Anaesthesiologist; WBC, white blood cell; BUN, blood urea nitrogen.

Table 8. Association of blood transfusion with adverse outcomes for all posterior cervical fusion patients.

\begin{tabular}{|c|c|c|c|c|c|}
\hline \multirow{2}{*}{ Outcome } & \multirow{2}{*}{$\begin{array}{l}\text { Not transfused }(\%) \\
\qquad(\mathrm{n}=886)\end{array}$} & \multirow{2}{*}{$\begin{array}{l}\text { Transfused }(\%) \\
\qquad(\mathrm{n}=89)\end{array}$} & \multicolumn{3}{|c|}{ Multivariate logistic regression ${ }^{\text {a) }}$} \\
\hline & & & Odds ratio & 95\% Confidence interval & $p$-value \\
\hline Deep surgical site infection & 1.0 & 1.1 & 1.06 & $0.11-9.40$ & 0.961 \\
\hline Venous thromboembolism & 1.4 & 4.4 & 2.45 & $0.73-8.80$ & 0.140 \\
\hline Surgical site infection & 1.2 & 0 & - & - & - \\
\hline Myocardial infarction & 0.2 & 3.4 & $10.45^{\text {b) }}$ & $1.42-77.12^{b)}$ & $0.021^{\text {bl }}$ \\
\hline Extended length of stay ( $>6$ day) & 20.7 & 61.8 & $4.42^{\text {b) }}$ & $2.68-7.29^{b)}$ & $<0.001^{\text {b) }}$ \\
\hline Death & 0.7 & 3.4 & 1.92 & $0.31-11.82$ & 0.479 \\
\hline
\end{tabular}

alEach line represent a separate multivariate logistic regression analysis for each variable and adjusted odds ratio and $p$-value by controlling for all demographics and comorbidities found in Table 1; ${ }^{\text {b }}$ Values in boldface indicate statistical significance $(p<0.05)$.

in the literature $[8,15,16]$. An increased rate of complications was demonstrated for all cervical spine fusion cases, for those with posterior fusion, those with ACDF, those with single level fusion and those for multilevel fusions. Although many studies have demonstrated that ACDF can be considered as an outpatient procedure due to low complication rates $[1,2,15]$ the results in this study demonstrate that cervical fusion complications due to transfusion warrant attention.

Our results demonstrate that all patients requiring transfusion after cervical fusion (anterior, posterior, multilevel or single level) are at increased risk of developing postoperative MI and require longer hospitalisation. Thus, patients receiving transfusion after cervical fusion should be monitored closely for cardiac events and may require longer than expected hospitalisation. Venous thromboembolism was also shown to be significantly increased in patients who had ACDF, multilevel or single level cervical fusion and transfusion. This indicates that these patients should be monitored closely for thromboembolism and raises questions about anticoagulation regiments for patient who are transfused. The database did not capture information about anticoagulation and is one of the limitations of this study but further studies are needed to clarify the need and the best anticoagulation protocols for such patients.

The analysis completed in this study also demonstrates that patients that undergo cervical spine fusion and re- 
ceive transfusion have an increased rate of mortality. This was shown for all patients as well as those who underwent ACDF and multilevel fusions. Although we could not identify the exact cause of death in the 30 days following surgery all these patients had increased risk of MI and venous thromboembolism, which can be assumed to be the cause of death. These results point to the importance of adequate postoperative investigations and more attention for patients who receive transfusion. In a recent study, Chen et al. [19] looked at mortality in patients who received transfusion in non-cardiac surgery. They concluded that increased rate of intraoperative transfusion can help reduce mortality among these patients. Therefore, transfusion requirements versus complications due to transfusion need to be analysed more closely and requires more investigation in the literature.

The financial effect of transfusion is also an important consideration. The cost of transfusion in the United States has been estimated to be between $\$ 522$ and $\$ 1,183$ (USD) [20]. Although the transfusion rate was low in cervical fusion patient, a total of 171 patients did require transfusion representing a cost between $\$ 89,262$ and $\$ 202,293$ in our cohort. In addition, the results of our study also showed an increased length of stay in hospital for patients who received a transfusion after cervical fusion. As mentioned by Yeom et al. [21] the estimated cost of each additional day spent at the hospital is close to $\$ 1,000$ USD. Thus, the cost of transfusion itself and added length of stay contribute to considerable economical implication of transfusion and cervical fusion surgeries.

One of the limitations of this study is that it is based on retrospectively collected data that only captures 30-day complications. Thus, longer follow-up and long term effects of transfusion were not identifiable. Although data acquisition in the NSQIP database is very well monitored certain parameters of interest for this study were missing; these include: type of cervical pathology, intraoperative blood loss, anticoagulation used, neurological outcomes, cause of death and adverse reaction to transfusion such as transfusion related acute lung injury or acute transfusion reactions. Additionally, it is unknown whether blood products were transfused intraoperatively or postoperatively. However, the large number of patients included in the database from all over the United States and Canada have advantages that outweigh these limitations. The results highlight 30-day complications due to transfusion and factors that can predict transfusion need in cervical spine fusion patients.

\section{Conclusions}

In this paper we investigate the effect of postoperative transfusion in cervical fusion patients on complications. We believe to be the first to present these results in a large cohort of patients form across North America. Our results demonstrate that although cervical fusion can be done as an outpatient procedure special precautions and investigation should be done for patients who receive transfusion after cervical fusion surgery. These patients are demonstrated to have higher rate of MI, deep vein thrombosis, wound infection and mortality when compared to those who do not receive transfusion. We also demonstrate that certain preoperative characteristics can be used to identify patients who require transfusion after cervical fusion surgery.

\section{Conflict of Interest}

No potential conflict of interest relevant to this article was reported.

\section{References}

1. McGirt MJ, Mehrlich M, Parker SL, Asher AL, Adamson TE. 165 ACDF in the outpatient ambulatory surgery setting: analysis of 1000 consecutive cases and comparison to hospital inpatient ACDF. Neurosurgery 2015;62 Suppl 1:220.

2. Sheperd CS, Young WF. Instrumented outpatient anterior cervical discectomy and fusion: is it safe? Int Surg 2012;97:86-9.

3. Baird EO, Egorova NN, McAnany SJ, Qureshi SA, Hecht AC, Cho SK. National trends in outpatient surgical treatment of degenerative cervical spine disease. Global Spine J 2014;4:143-50.

4. Bohl DD, Webb ML, Lukasiewicz AM, et al. Timing of complications after spinal fusion surgery. Spine (Phila Pa 1976) 2015;40:1527-35.

5. Blumberg N. Allogeneic transfusion and infection: economic and clinical implications. Semin Hematol 1997;34(3 Suppl 2):34-40.

6. Osterhoff G, Burla L, Werner CM, et al. Role of preoperative blood transfusion and subcutaneous fat thickness as risk factors for surgical site infection af- 
ter posterior thoracic spine stabilization. Surg Infect (Larchmt) 2015;16:333-7.

7. Innerhofer P, Walleczek C, Luz G, et al. Transfusion of buffy coat-depleted blood components and risk of postoperative infection in orthopedic patients. Transfusion 1999;39:625-32.

8. Basques BA, Anandasivam NS, Webb ML, et al. Risk factors for blood transfusion with primary posterior lumbar fusion. Spine (Phila Pa 1976) 2015;40:1792-7.

9. Hasegawa K, Homma T, Chiba Y, Hirano T, Watanabe K, Yamazaki A. Effects of surgical treatment for cervical spondylotic myelopathy in patients $>$ or $=70$ years of age: a retrospective comparative study. J Spinal Disord Tech 2002;15:458-60.

10. Boakye M, Patil CG, Santarelli J, Ho C, Tian W, Lad SP. Cervical spondylotic myelopathy: complications and outcomes after spinal fusion. Neurosurgery 2008;62:455-61.

11. Romano PS, Campa DR, Rainwater JA. Elective cervical discectomy in California: postoperative inhospital complications and their risk factors. Spine (Phila Pa 1976) 1997;22:2677-92.

12. Birkmeyer JD, Shahian DM, Dimick JB, et al. Blueprint for a new American College of Surgeons: National Surgical Quality Improvement Program. J Am Coll Surg 2008;207:777-82.

13. Raval MV, Dillon PW, Bruny JL, et al. Pediatric American College of Surgeons National Surgical Quality Improvement Program: feasibility of a novel, prospective assessment of surgical outcomes. J Pediatr Surg 2011;46:115-21.

14. Carabini LM, Zeeni C, Moreland NC, et al. Development and validation of a generalizable model for predicting major transfusion during spine fusion surgery. J Neurosurg Anesthesiol 2014;26:205-15.

15. Martin CT, Pugely AJ, Gao Y, Mendoza-Lattes S. Thirty-day morbidity after single-level anterior cervical discectomy and fusion: identification of risk factors and emphasis on the safety of outpatient procedures. J Bone Joint Surg Am 2014;96:1288-94.

16. Manning BT, Sankaranarayanan S, Hassanzadeh H, et al. The utility of obtaining routine hematological laboratory values following an anterior cervical diskectomy and fusion. Spine (Phila $\mathrm{Pa}$ 1976) 2014;39:E1228-32.

17. Lin CK, Lin CL, Feng YT, et al. Economic burden of routine hematologic tests and intensive care unit observation for elective anterior cervical discectomy and fusion. J Chin Med Assoc 2014;77:26-30.

18. Alam MM, Sobani ZA, Shamim MS, Ahmad K, Minai F. Primary elective spine arthrodesis: Audit of institutional cross matched to transfused $(\mathrm{C} / \mathrm{T})$ ratio to develop blood product ordering guidelines. Surg Neurol Int 2013;4(Suppl 5):S368-72.

19. Chen A, Trivedi AN, Jiang L, Vezeridis M, Henderson WG, Wu WC. Hospital blood transfusion patterns during major noncardiac surgery and surgical mortality. Medicine (Baltimore) 2015;94:e1342.

20. Shander A, Hofmann A, Ozawa S, Theusinger OM, Gombotz H, Spahn DR. Activity-based costs of blood transfusions in surgical patients at four hospitals. Transfusion 2010;50:753-65.

21. Yeom JS, Buchowski JM, Shen HX, Liu G, Bunmaprasert T, Riew KD. Effect of fibrin sealant on drain output and duration of hospitalization after multilevel anterior cervical fusion: a retrospective matched pair analysis. Spine (Phila $\mathrm{Pa} 1976$ ) 2008;33:E543-7. 